\title{
FRAMEWORK FOR DEVELOPED SIMPLE ARCHITECTURE ENTERPRISE - FDSAE
}

\author{
Nieto Bernal Wilson ${ }^{1}$ and Luna Amaya Carmenza ${ }^{2}$ \\ ${ }^{1}$ Department of Systems Engineering, Universidad Norte- \\ wnieto@uninorte.edu.co \\ ${ }^{2}$ Department of Industrial Engineering, Universidad Norte- \\ cluna@uninorte. edu.co
}

\begin{abstract}
In This article presents a framework for develop de Architecture enterprise based on the articulation of emerging paradigms for architecture development of information enterprise [1]. The first one comes from the agile methods and it is inspired on the Scrum model which aim to simplify the complex task of developing a quality software, the second the processes models whose are oriented the development of Architectures Enterprise as Zachman and TOGAF in a paradigm of the Model Driven and principles de reference de architecture de Software form the paradigms Generation (MDG), these approaches are integrated eventually leading to the formulation and presentation of an framework for developed simple architecture enterprise FDSAE- The goal is to present a simple, portable, understandable terms enabling, modeling and design business information architecture in any organizational environment, in addition to this, there are important aspects related to the unified Modeling Language UML 2.5 and the Business Process Modeling BPMn that become tools to obtain the products in the FDSAE Framework, This framework is an improved version of Framework MADAIKE [2] developed by the same authors.
\end{abstract}

\section{KEYWORDS}

Attributes Quality Performance, Architecture Enterprise, Business Process, Software Process, Metrics, Model Drive Generation, Views, Viewpoints.

\section{INTRODUCTION}

The construction of information systems in today's complex, to meet the demanding needs of organizations especially motivated by the technological trends, new business opportunities in the global economies, the development of business strategies, the integration of services, continuous improvement of processes in the organization and continued competition in markets increasingly require the support of computer systems to ensure functionality, security, scalability, elasticity, maintenance, capacity and availability among others. Given these new challenges software architects must have tools, processes, techniques and frameworks to resolving these challenges and get IT solutions with excellent quality attributes. In this paper display a simple and extended framework that allows to develop baseline architecture and target architecture of an organization in order to provide effective response to business needs is presented basically the FDSAE is a methodology that is based on the process abstraction and separation of layers and using modeling Natarajan Meghanathan et al. (Eds) : WiMONe, NCS, SPM, CSEIT - 2014 pp. 271-284, 2014. (C) CS \& IT-CSCP 2014

DOI : $10.5121 /$ csit.2014.41222 
tools can draw a scale model of the software system, on which they can make decisions and achieve launch a plan to mitigate the gaps between the current system and the ideal system within transition of the organizational. In Figure 1 the general structure shown FDSEA is proposed framework. In this one composed of seven views structure is shown: Planning, Business, Business Process, Data, Applications, Infrastructure, Safety. Accompanied by two phases of coverage, Government Enterprise Architecture and Quality Attributes (performance).

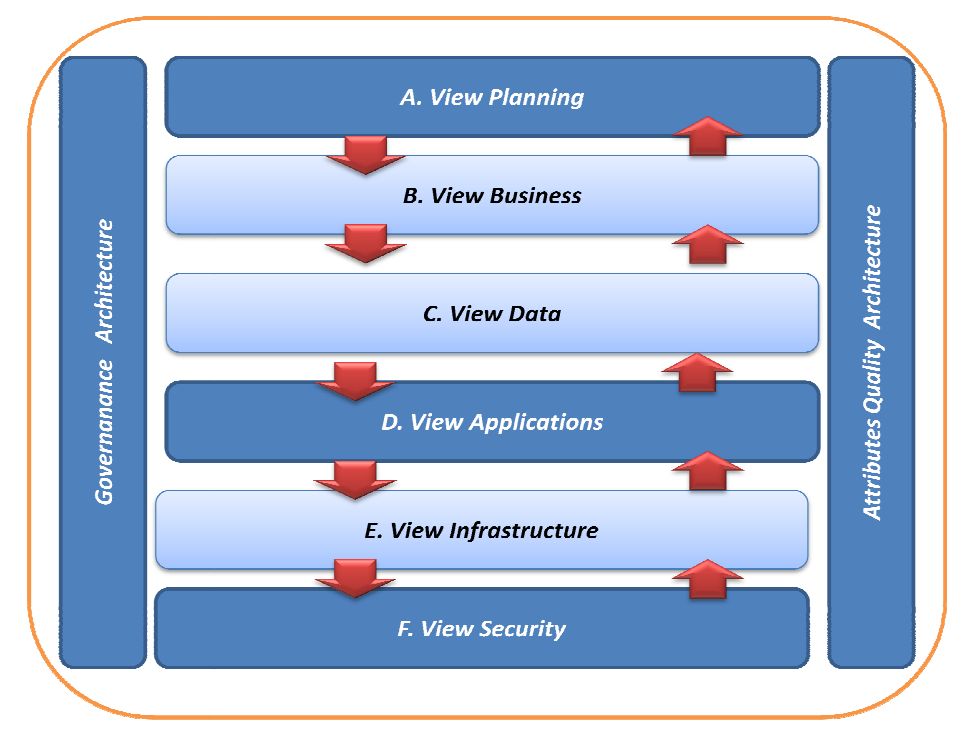

Figure 1. Methodology Structure-FDSEA-

\section{RESEARCH METHODOLOGY}

The following are the phases of exploratory research that conceptually possible to establish the methodology FDSEA, two phases were developed and are described as follows:

\subsection{Phase I: Analysis of development standards for $E A$ (state of the art)}

This phase was aimed to evaluate the different standards, tools and process for the development of enterprise architecture (EA) on the basis of paradigm MDG (Generation Driver Modeling), in this present there are several technologies such as SysML, Zachman Framework, Togaf, SOMF, and UPDM each with different approaches and techniques to address the development of the EA. $[13,14,15.16]$.

Model Driven Generation (MDG) Technologies: MDG Technologies allow users modeling capabilities to specific domains and notations.

\section{Features:}

- Helps align business processes and IT to the business strategies and goals.

- Provides support for at the phases in the ADM 
- Provides support for OMG's Business Motivation Model • Provides support for the Architecture Content Model · Provides support for visual modeling of As-Is and To-Be architecture

- Provides support for modeling at four architecture domains specific to TOGAF (Business, Application, Data and Technology)

- Provides support for the report generation of TOGAF work products

The Systems Modeling Language (SysML): is a visual modeling language for systems engineering applications. It supports the specification, analysis, design, verification and validation of a broad range of systems. These systems may include network, infrastructure IT, hardware, software, information, processes, personnel, and facilities. SysML is a specified as a profile (dialect) of the Unified Modeling Language ${ }^{\mathrm{TM}}$ (UML ${ }^{\mathrm{TM}}$ ). [2],[15].

\section{Features:}

- Specify, design and analyze complex system models

- Model with all 9 diagrams for SysML.

- Visualize and trace requirements to model elements throughout the entire development lifecycle.

- Custom Search Facility: Perform complex searches, view SysML Allocations and generate reports from the results.

- Support for XMI 2.0, XMI 2.1 and UML 2.x

DDS, Data Distribution Service: DDS is a specification and an interoperability wire-protocol that defines a data-centric publishes-subscribe architecture for connecting anonymous information providers with information consumers. is a standard widely used for developing the architecture of real-time systems is the specification for a middleware type publish/subscribe distributed systems, DDS has been created with the purpose of serving the needs of industry standardize data-centric systems [2].

\section{Features:}

- Specify Data-Centric Publishers, Subscribers, Topics and QoS Policies.

- Define Data Local Reconstruction mappings for effective DDS data access.

- Target DDS implementations for the Open Splice and RTI platforms.

Framework Zachman ${ }^{\mathrm{TM}}$ : The Zachman Framework ${ }^{\mathrm{TM}}$ typically is depicted as a bounded $6 \times 6$ "matrix" with the Communication Interrogatives as Columns and the Reification Transformations as Rows. This matrix would necessarily constitute the total set of descriptive representations that are relevant for describing something. Anything: in particular an enterprise. (www.zachman.com, 2014), The Zachman Framework ${ }^{\mathrm{TM}}$ is an Enterprise Architecture framework for enterprise architecture, which provides a formal and highly structured way of viewing and defining an enterprise. It consists of a two dimensional classification matrix based on the intersection of six communication questions (What, Where, When, Why, Who and How) with six levels of reification, successively transforming the abstract ideas on the Scope level into concrete instantiations of those ideas at the Operations level. 


\section{Features}

- Displays the EA from different perspectives: Executive Management, Process, Architecture, Engineering and Technology.

- Identification, Definition, Representation, Specification, Configuration and Instantiation (Inventory, Process, Networks, Responsibility, Timing cycles and Motivation intentions.

The Open Group Architecture Framework (TOGAF): TOGAF is an architecture framework widely accepted in the industry that provides the methods and tools to assist in the acceptance, production, use and maintenance of an enterprise architecture. It is based on an iterative process model supported by best practices, and a set of reusable assets from existing architecture.

\section{Features}

- Implement all phases of the TOGAF Architecture Development Method (ADM).

- Create visual models of As-Is and To-Be architecture.

- Model all four TOGAF architecture domains: Business, Application, Data and Technology

UPDM, the Unified Profile for DoDAF/MODAF (UPDM) is the product of an Object Management Group (OMG) initiative to develop a modeling standard that supports both the USA Department of Defense Architecture Framework (DoDAF) and the UK Ministry of Defense Architecture Framework (MODAF). The MDG Technology for UPDM provides a model-based framework for planning, designing and implementing the Unified Profile for DoDAF and UPDM architectures. Source: www.sparxsystem.com, and [2].

\section{Features}

- Create architectural models for complex system-of-systems, which may include hardware, software, data, personnel and organizations.

- Define consistent, accurate architectures with clear separation of concerns to describe services, systems, operations, strategies and capabilities.

- Analyze, specify, design, and verify system models using appropriate levels of abstraction.

- Employ a rigorous, standards based approach to defining and exchanging architecture information using UML, XMI and related standards.

SOMF ${ }^{\mathrm{TM}}$ is a model-driven engineering methodology whose discipline-specific modeling language and best practices focus on software design and distinct architecture activities, employed during various stages of the software development life cycle. Moreover, architects, analysts, modelers, developers, and managers employ SOMF to tackle enterprise architecture, application architecture, service-oriented architecture (SOA), and cloud computing organizational challenges.

\section{Features}

- To achieve these underpinning milestones, six distinct software development disciplines offer corresponding models whose language notation guide practitioners in designing, architecting, and supporting a service ecosystem: Conceptual Model, Discovery and 
Analysis Model, Business Integration Model, Logical Design Model, Architecture Model and Cloud Computing Toolbox Model.

\subsection{Phase II: Description of components Framework for developed simple architecture enterprise-FDSAE-}

\subsubsection{The View Planning Architecture:}

Planning view aims to develop a comprehensive project plan to address the development of the baseline architecture and target architecture of the organization, which implies:

\section{Identify and understand the context of the system (organization) and defining enterprise}

- Understand the proposed framework FDSAE

- Establish the scope, objectives and goals of the project.

- Establish the requirements for architecture work.

- Defining the Architecture Principles that will inform any architecture work.

- Evaluating the enterprise architecture maturity

- Estimate cost and effort.

- Identify work products to be developed

- Prepare budget and schedule

- Define and ready tools for architecture development

- Manage the project team

- Manage project risks

- Migration Plan

- Present, Socialize and obtain approval of the general project plan

Outputs: The general project plan and models preliminary of the architecture enterprise (example: Models Blocks Construction or Models of Context).

\subsubsection{The View Business Architecture:}

It is a layer composed of a set of models that allows visualizing the organization strategic objectives and facilitates decision making related to the integration and development of IT assets [6 and 7]. It is based on the paradigm of Enterprise Architect's Model Driven Generation (MDG) Technology, through which we obtain the following models such as: the strategic model, the Balanced Scorecard, Strategy Map, Value Chain, Decision Tree and process model organizational structures (will not be better or better organizational structure based process model organizational structure). The business architecture allows in-depth view of the system context and on this basis to establish the principles that guide the development of the following layers of the business information architecture.

Outputs: The Strategic Model, Model Chain Value, Model Organizational Structure, Model Geographic Distribution Enterprise, Model Business Process, Business Data Model and deployment General model. 
Additionally other products that depend on the nature of the project and the current state of the architecture baseline may be included.

Products: Model business processes (Notation BPMn) Organizational Structure Model business (organizational structure), model high-level processes (BPMn Orchestration), Model Geographic Distribution business (model nodes), model work flows (BPMn) Model Integration work flows (BPM) with SOA, Strategy Map (Norton and Kaplan), Value Chain (Michael Porter), BSC (and Kaplan and Norton), Vision, Mission and Business Objectives.

\subsubsection{View Data Architecture}

A layer composed of a set of models to display the organization infrastructure integrated information, partly from conceptual models to reach the physical design of the database, data warehouses and repositories of information, Here are the models[6,7,8,]: Model of Organizational Information Objects, Logical Data Model (high level Master and Transactional), Logical Data Model (detailed), database design (physical), General Design Model and Data Warehouse Model and design of integrated repositories and. Dictionary of Data.

Outputs: Data Model Conceptual, Data Model detailed, Repository System Model, Data Warehouse and Model database design (physical),

Additionally other products, from information architecture, aims to achieve the following products: the object model Organizational Information (UML domain model) Object Model master and transactional information (object relational model), database design from information objects (physical) (database model), the Enterprise Information Integration (EEI), here is the implementation of the data model using the DBMS along with the modeling and design of Data Warehouse and Information Repositories.

\subsubsection{View Applications Architecture}

It is a layer composed of a set of models to display the application infrastructure, like the previous layer of conceptual models to reach physical model implementation level, in models describing this layer are: the model of high-level components, the component model and services detailed model of services, applications and software components, the integrated model (services, applications and components sw) and extended system design or distributed, (production platform).

Outputs: Component Model Conceptual, Component Model detailed, Services Model and Component design (physical),

\subsubsection{Infrastructure Architecture}

It is a layer composed of a set of models to visualize infrastructure hardware components, devices, connectivity networks that support communication processes, transfer of data, voice and content. Within models and systems that describe these layers are: Model business logistics system, distributed system architecture, Distributed System Design, Architecture technology and network architecture connectivity [7, 8, 9 and 10]. 
Outputs: Deployment Model Conceptual, Deployment Model detailed Deployment design (physical) and Style Architecture (Distributed, Virtual, Cloud and others).

Additionally other products from infrastructure architecture, aims to achieve the following products: The physical distribution model of the business (geographical node model), the model of the physical distribution business (networking) (network diagrams), the networking Design (network design), the design of the physical layout of the business (Lan, Man, Wan, Wireless, Pan) and physical layout design extended Extend Business Networking (backbone networks, transport networks, access networks and networks end user).

\section{DESCRIPTION OF LAYERS, PHASES AND ROLES (FDSEA)}

The FDSAE can be viewed as a multilayer model composed of six layers, see figure 1, In this case: Architecture Business, Architecture Data, Architecture functions, Architecture Infrastructure Architecture and architecture security. Plus two supporting layers made up of Governance of the architecture and Attribute Quality Architecture.

A. The View Planning Architecture: Business analysts, Board and Team architecture IT: Mainly to assume the role of set of business analysts, Board, and team architecture IT, who is the one responsible to identify, prioritize, structure and planning architectures, defining the enterprise, Identifying key drivers and elements in the organizational context, Defining the Architecture Principles, Defining the framework to be used, Defining the relationships between management frameworks, Evaluating the enterprise architecture maturity and analyze the different topics associated with IT product benchmarking and trend analysis associated with technological product to develop.

B: Business Architecture: Business Architect IT: Mainly assumes the role of Business Architect is the one who takes care of modeling, design and business structure seen this as modeling of the structure of processes (BPM), organization, workflow, (WK) weather events (time line), identification of service components (SOA) and business strategic modeling (strategy map).

C: View Data Architecture: Information Architect: Mainly assumes the role of Information Architect is the one who is responsible for identifying and modeling Organizational Information objects (classes, objects, tables), the description of information objects both teachers and transactional (relational data model objects), design database from information objects (physical database), Enterprise Information Integration (EEI), Database, Data Repository, Data Warehouse Design and Repositories Information used in this case comprehensively the DBMS.

D: View Applications Architecture: Application Developer: Mainly it assumes the role of Application Architect is the one who is responsible for developing the architecture applications, the description of high-level software components, the modeling software components and services described the Design Component software and services detailed integration of software components and services detailed and extended system design and component-based distributed software.

E: View Infrastructure Architecture: Mainly it assumes the role of infrastructure is the architect who is responsible for modeling, design Infrastructure Architecture, the physical layout 
description of the business, the modeling of the physical distribution business (networking), the design of the physical layout of the business (network), the deployment of physical distribution business (Lan, Man, Wan, Wireless, Pan) and extended physical distribution Design BusinessNetworking Extend-

F: View Security Architecture: Security Engineer: Mainly it assumes the role of Security Engineer, who is responsible of Identify risks architecture, define Security policies define the architecture, Organization security architecture, Identify the Security architecture users, management of the Access control architecture, Encryption and data protection architecture, Security Infrastructure, Application security and Security Compliance regulations architecture.

Parallel phase: The Governance Architecture: Business Architect: Mainly it assumes the role of Lider Team or Business Architect, who is responsible of Management a enterprise architecture consisting of business process, information, data, application and technology architecture layers for effectively and efficiently realizing enterprise and IT strategies by creating key models and practices that describe the baseline and target architectures. The architect defines and applies requirements for taxonomy, standards, guidelines, procedures, templates and tools, and provides a linkage for these components. Improve alignment, increase agility, improve quality of information and generate potential cost savings through initiatives such as re-use components the architecture.

Parallel phase: Attributes Quality Architecture: IT Architect: Mainly assumes the role of IT Architect who is the one responsible to identify, describe the Quality attributes are properties that comprehensively provide the architecture to stakeholders, are quantitative measures and qualitative the system, some examples of quality attributes by which stakeholder's assessment the quality of software systems are: Performance, security, modifiability, reliability, usability, calibrates ability, availability, throughput, configurability, Subset ability and reusability. Also the quality attributes of the software allow you to set the degree to which a software system meets its requirements for quality attributes depends on its architecture. Architectural decisions are made to promote different quality attributes. A change in architecture to promote a quality attribute often affects other quality attributes. Architecture provides the basis for achieving quality attributes, but it is useless if they did not adhere to the application.

\section{DESCRIPTION OF PRODUCTS (FDSAE)}

The following describes the different products to develop as a result of the application of FDSEA well: Some of the representations used in the framework of the methodology shown in figures 2, $3,4,5,6,7,8$, and 9 . 


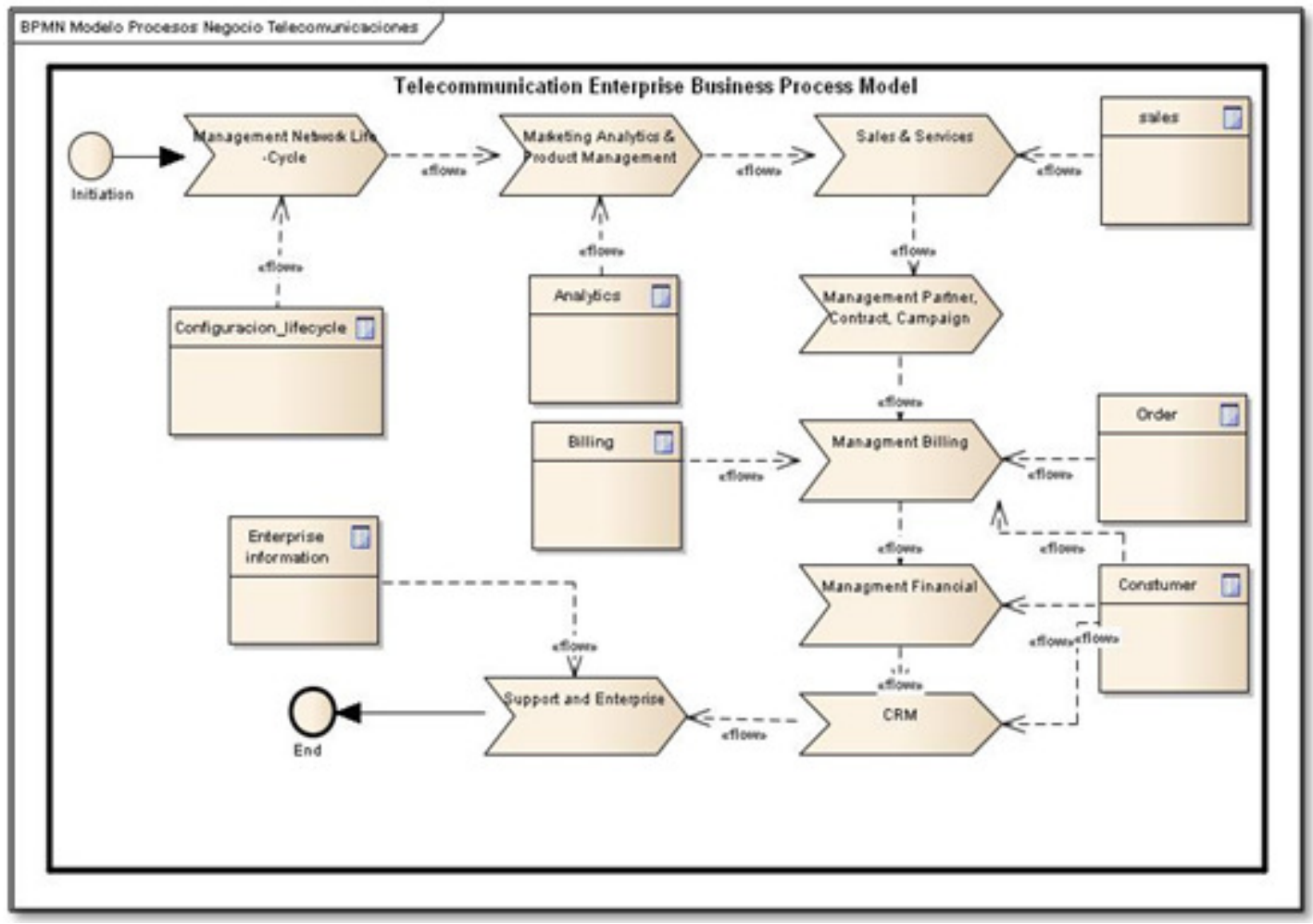

Figure 2.View Business Architecture

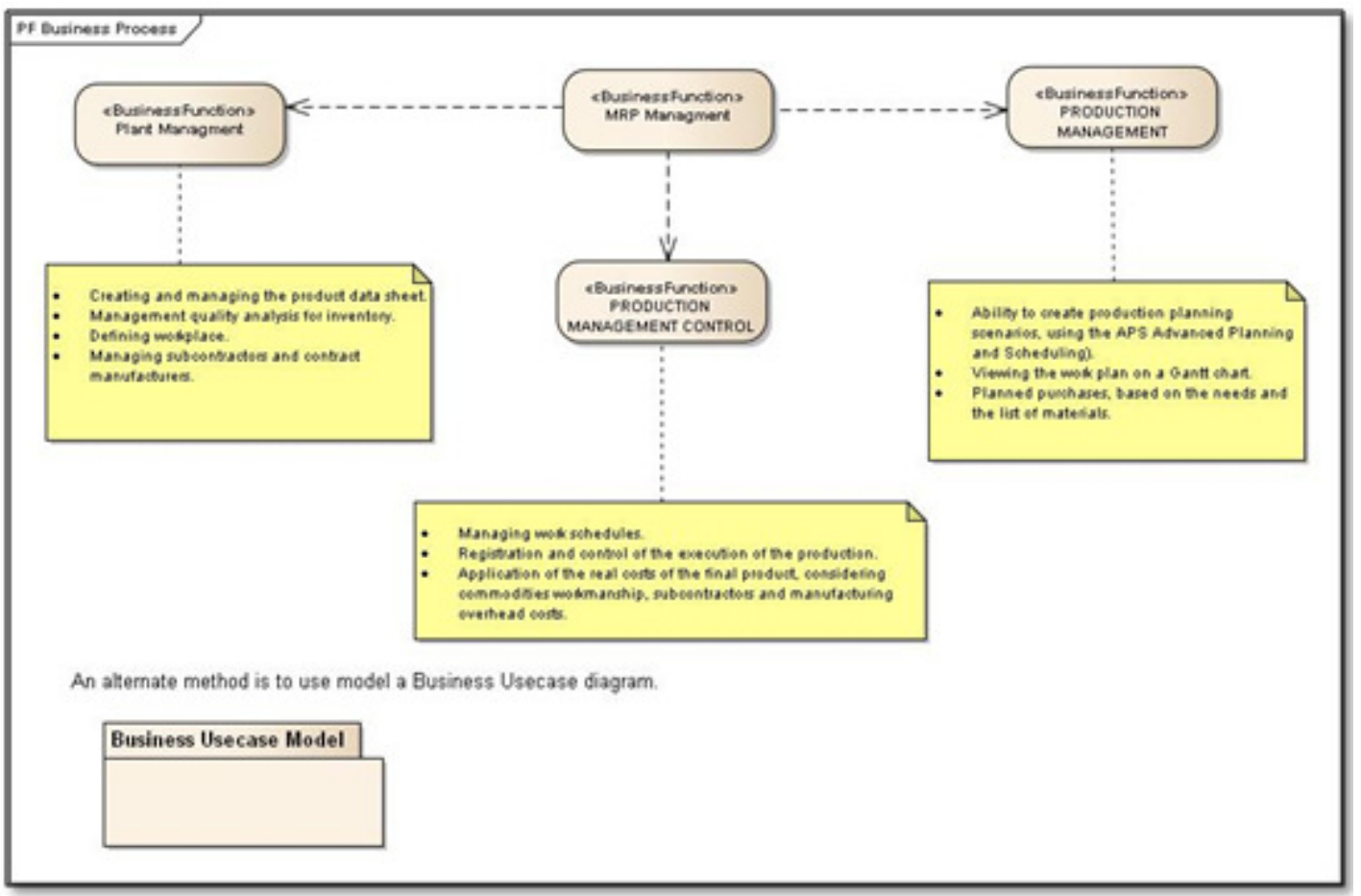

Figure 3. Plant Modeling 


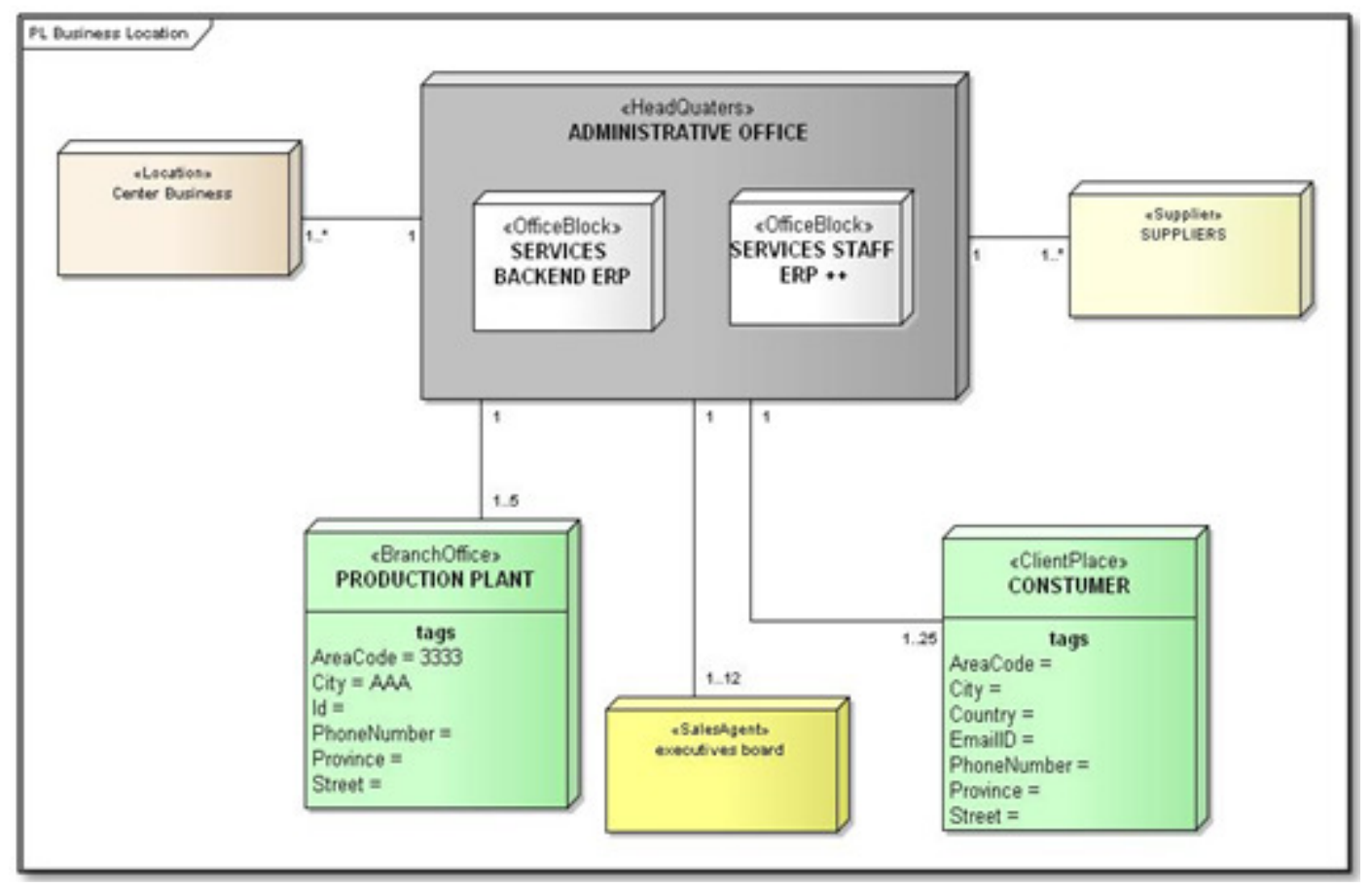

Figure 4. Geographic Distribution Business Model

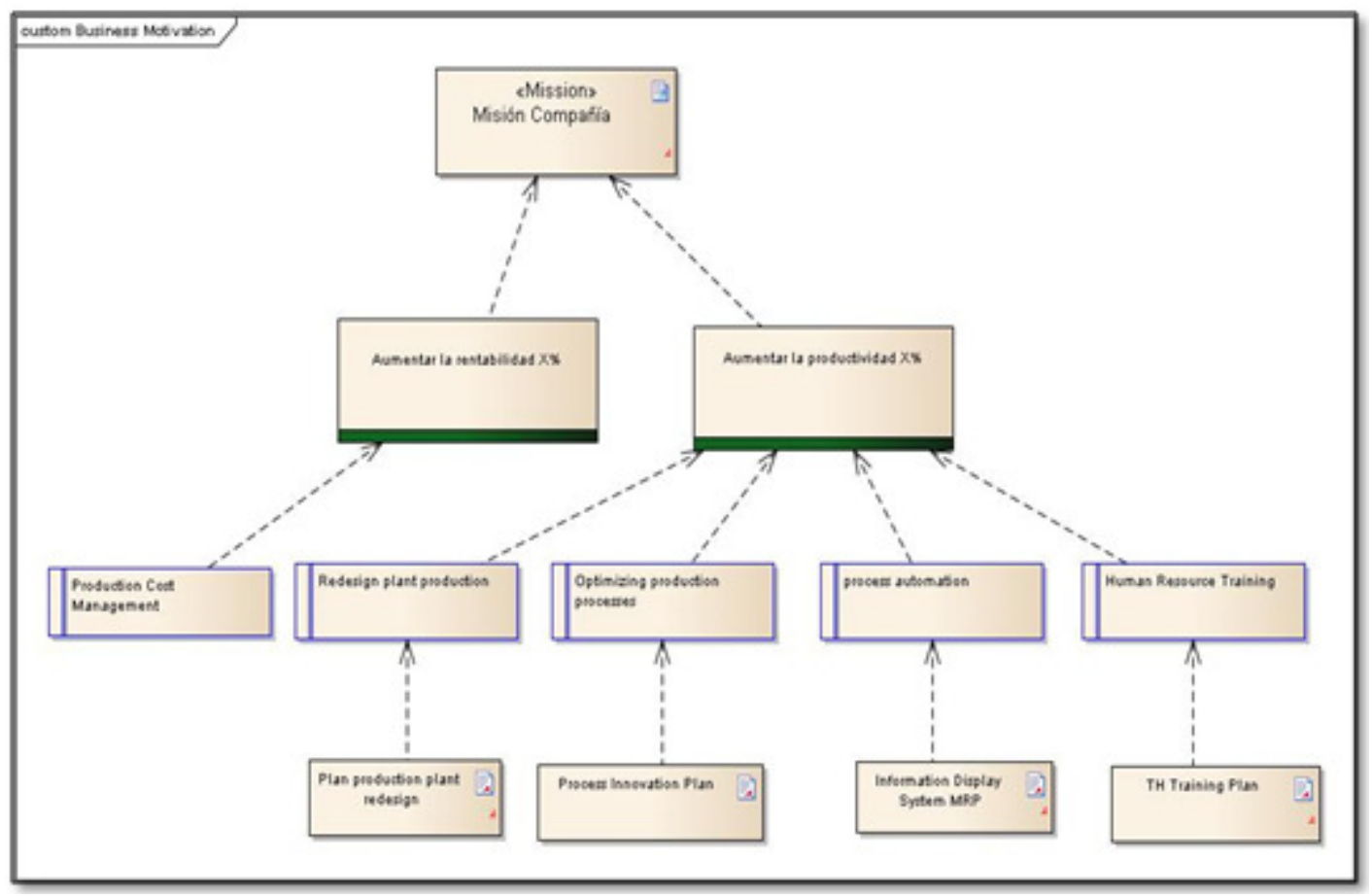

Figure 5. Motivation custom business 


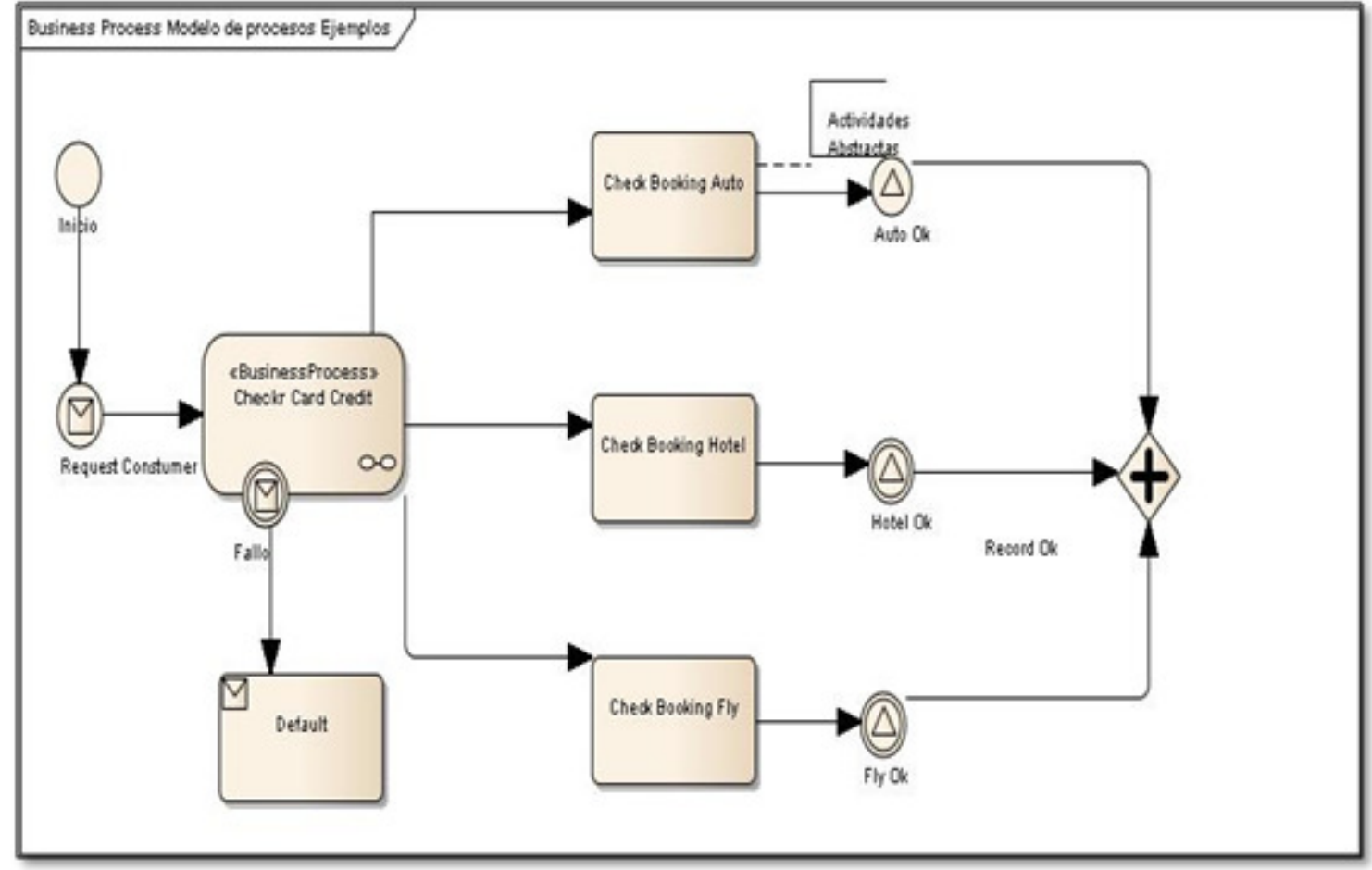

Figure 6. Activity Diagram Purchase Order Process

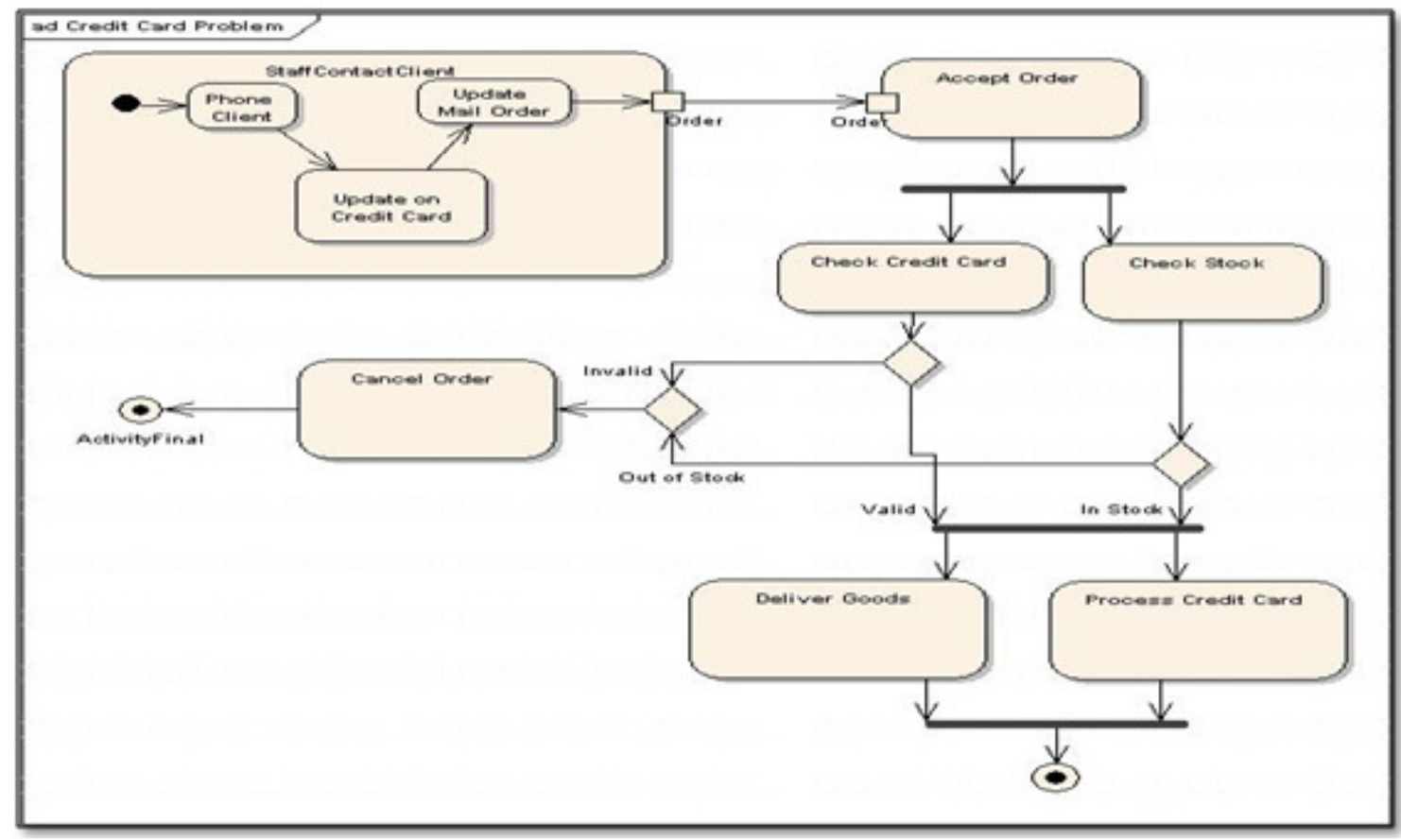

Figure 7.Business Workflow 


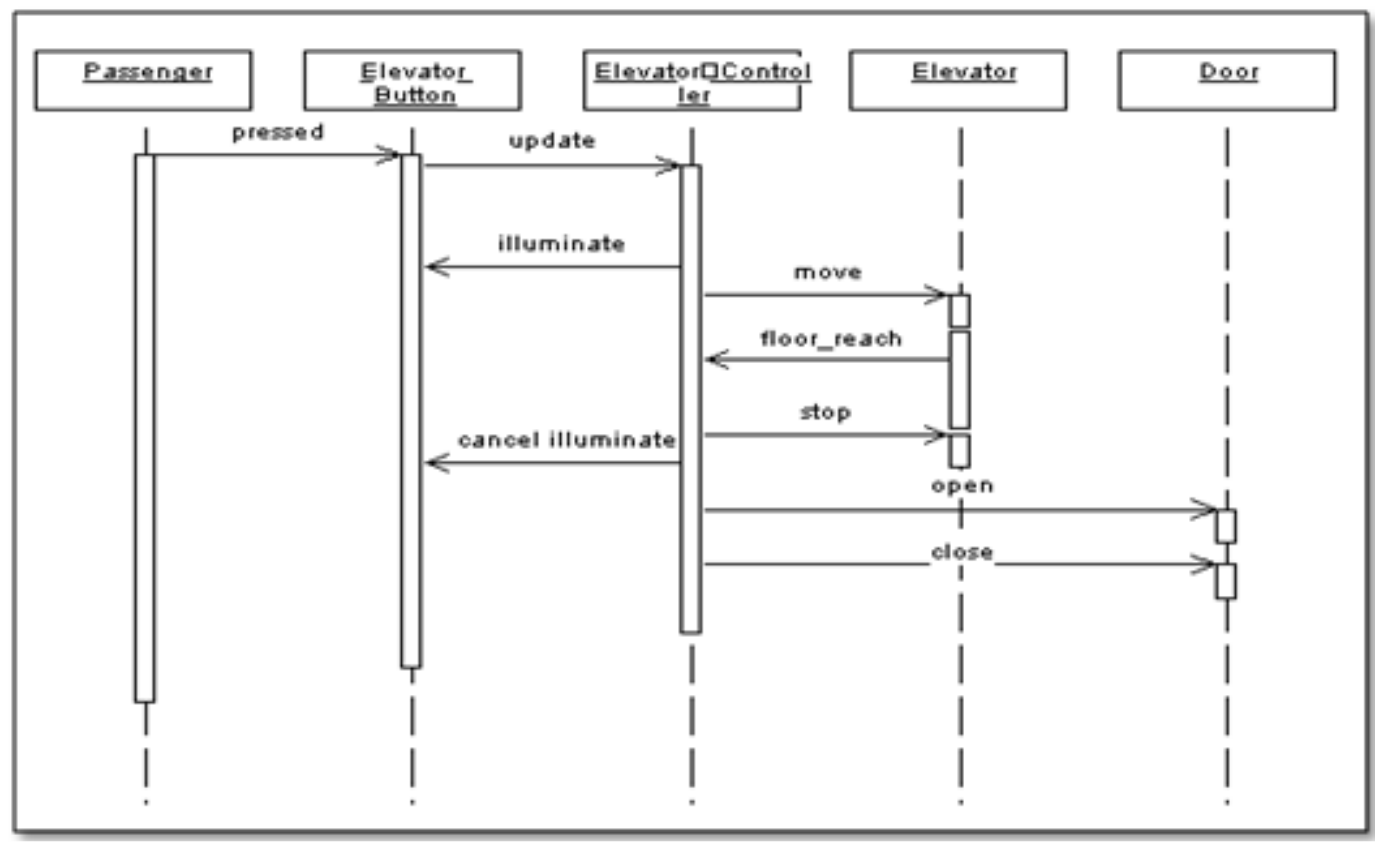

Figure 8. Sequence Diagram

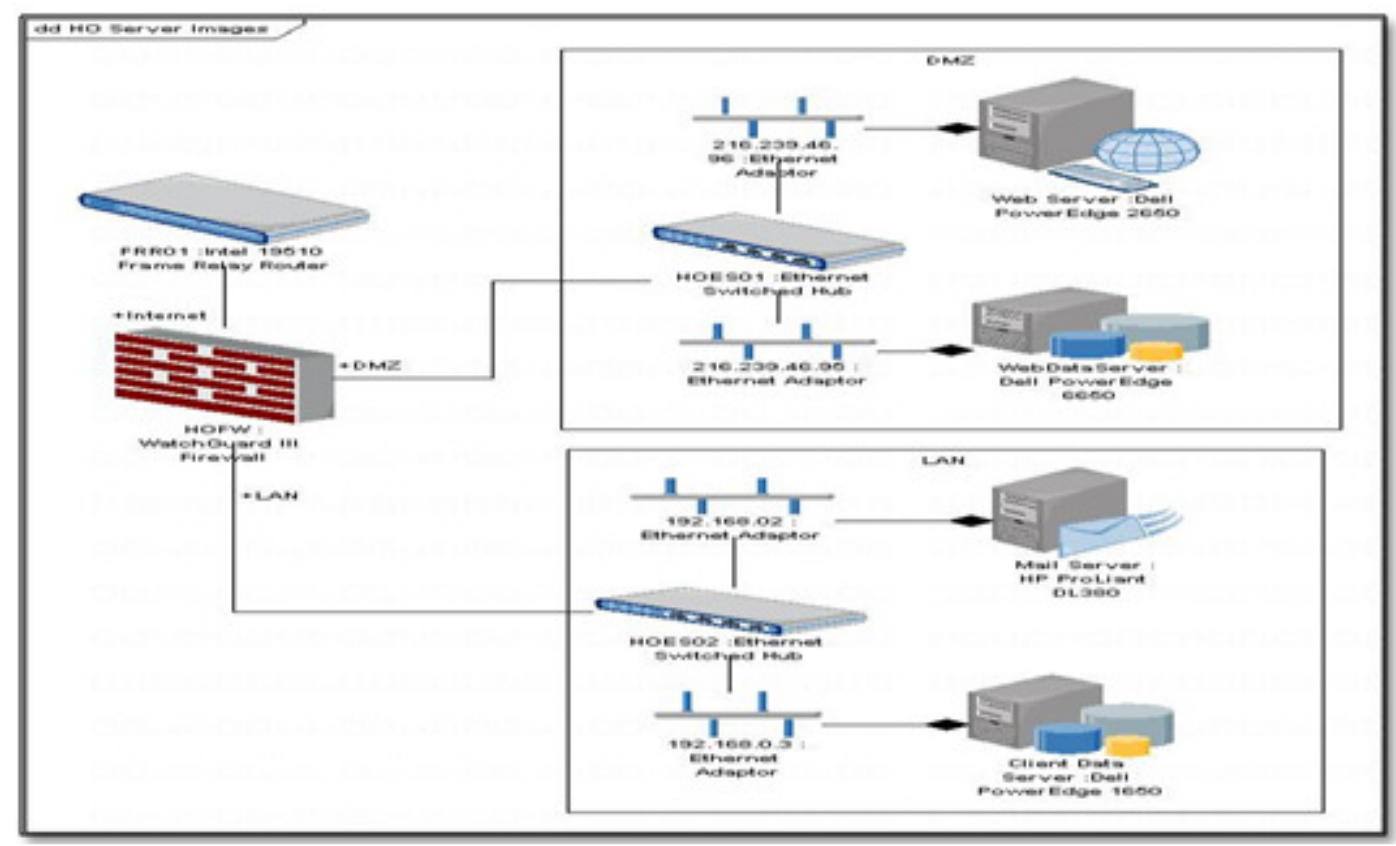

Figure 9. Deployment Model: source: www.sparxsystems.com 


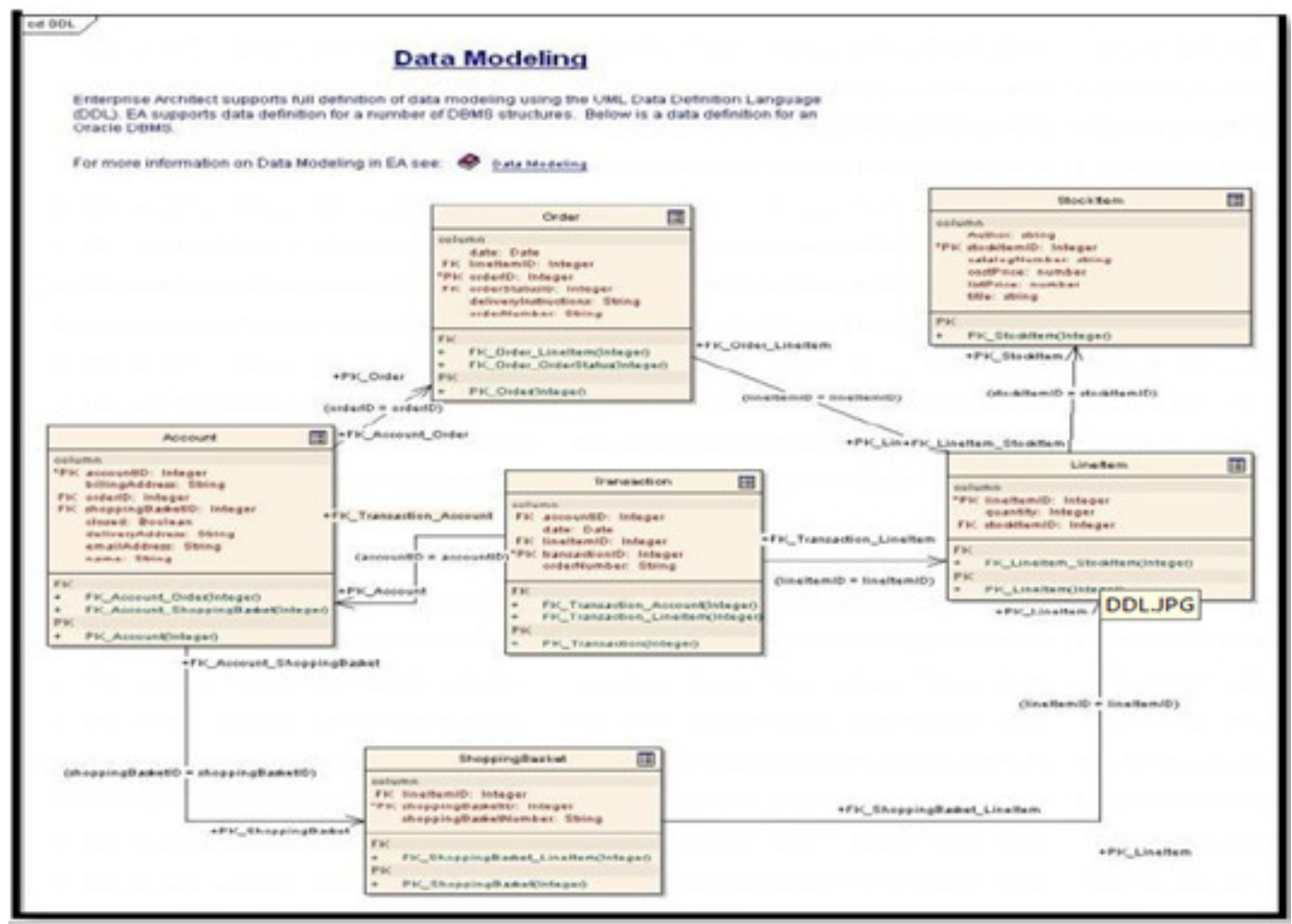

Figure 10. Domain Model source: www.sparxsystems.com

\section{CONCLUSION}

In this paper we demonstrate that FDSAE multilayer architecture, you can simplify complex tasks when developing quality software based on agile methods, with reference to processes oriented towards the development of enterprise information architectures which provides a standardized set of tools for project planning.

It is also important to note that the methodology objective sought to represent project phases ranging from the conceptual perspective, logic, implementation, integration and extended. In this way structure composed of layers methodology and phases resulting in a matrix model.

The methodology FDSEA can be applied to any project, regardless of size, complexity, additionally can use any tool case that supports UML 2.5 to develop different models and diagrams.

\section{ACKNOWLEDGMENT}

Financed Project with resources, "Patrimonio Autónomo Fondo Nacional de financiamiento para la Ciencia, la Tecnología y La Innovación, Francisco José De Caldas”, Proyecto 1215-502-27951 ACESCO-UNIORTE-COLCIENCAS (Colombia). 


\section{REFERENCES}

[1] Godinez, M. Eberhard, H. Klaus, K. The Art of Enterprise Information Architecture, 2010, IBM Press.

[2] NietoBernal W. LunaAmaya C, Framework MADAKEI, 2014, ickse, 2014

[3] Burlton, Roger. Business Process Management: Profiting From Process. Indianapolis, IN: Sams Publishing May 2001.

[4] Chris, R. Introduction to Business Architecture, 2010, Cengage Learning.

[5] Carla Marques Pereira, Pedro Sousa, A Method to Define an Enterprise Architecture using the Zachman Framework, 2004.

[6] Crosby, Philip. Quality without Tears. New York: McGraw-Hill, 1984.

[7] Frank Goethals Jacques VandenbulckeWilfriedLemahieu, Developing the Extended Enterprise with the FADEE, 2004

[8] Gerald R. Khoury, Simeon J. Simoff, 2010, Enterprise Architecture Modelling Using Elastic Metaphors.

[9] Jeanne, W. Peter, W, Davd, C. Enterprise Architecture as Strategy, Harvard Business Press, 2006

[10] MDG Technology For Zachman, Framework User Guide, Copyright 2007-2008 Sparx Systems Pty Ltd

[11] The Open Group's approach to information systems architecture. Togaf.

[12] Model-based framework for planning, designing and implementing the Unified Profile for DoDAF and MODAF (UPDM) architectures.

[13] William Hudson, Enterprise Information Architecture: Strategies for the Real World, 2003.

[14] FDI-Intelligence, FT Business Financial Times. The fDI report 2012 Global greenfield investment trends, 2012

\section{WEBLINKS}

[15] www.sysml.org

[16] www.sparxsystem.com

[17] www.omg.org

[18] www.zachman.com

[19] www.opengroup.org/togaf/

[20] www.pmi.org

\section{AUTHORS}

Wilson Nieto Bernal is Systems Engineer and Specialist Software Engineering, Universidad Industrial de Santander (UIS) Colombia, Master /Expert in Technology Management, Master of Computer and PhD in Computer Science, ULPGC-Las Palmas GC. (Spain), 2007, with extensive experience in project management R\&D in the area of Information Technology and Applications, Knowledge management Organizational Models for software development.

Carmenza Luna Amaya: is Industrial Engineering, and a $\mathrm{PhD}$ in Industrial Engineering from the Universidad Politecnica de Valencia, Spain, with extensive experience in research, development and organizational innovation, currently teaches at the University of the North. 